\title{
Artificial vision system for the prevention of injuries in the upper back and neck areas based on the OpenPose algorithm
}

\section{Sistema de visión artificial para la prevención de lesiones en las zonas de espalda alta y cuello basado en el algoritmo de OpenPose}

GARCÍA-CERVANTES, Heraclio †*，CARDONA-VILLALPANDO, Juan Carlos, BLANCOMIRANDA, Alan David and CARRILLO-HERNÁNDEZ, Didia

\author{
Universidad Tecnológica de León \\ ID $1^{\text {st }}$ Author: Heraclio, García-Cervantes / ORC ID: 0000-0002-4229-9229, Researcher ID Thomson: X-5622-2019, \\ CVU CONACYT ID: 290829
} ID $1^{\text {st }}$ Coauthor: Juan Carlos, Cardona-Villalpando / ORC ID: 0000-0002-2571-892X, Researcher ID Thomson: ABF-
1633-2020, CVU CONACYT ID: 1095804 ID $2^{\text {nd }}$ Coauthor: Alan David, Blanco-Miranda / ORC ID: 0000-0002-8595-8634, Researcher ID Thomson: W-9701-2019,
CVU CONACYT ID: 298274

ID $3^{\text {rd }}$ Coauthor: Didia, Carrillo-Hernández, ORC ID: 0000-0001-9989-5884, Researcher ID Thomson: ABF-4839-2020, CVU CONACYT ID: 936937

DOI: $10.35429 /$ EJT.2020.8.4.13.19

Received October 12, 2020; Accepted December 06, 2020

\begin{abstract}
Computer vision is a tool used to understand images that have been analyzed and processed. And in health and human body applications it is no exception, since they help to vectorize the body and its movement, analyzing the changes between them. The main objective of this work is to develop an interactive mobile application for the monitoring, description and recording of body postures in the neck and upper back areas when using cellular devices. The OpenPose algorithm is used to identify and register the specific points of the established zones. In the analysis process, the Keras framework is used in order to build a deep learning convolutional neural network. A graphical user interface is designed in order to facilitate the use and interpretation of measurements. In addition, it is accompanied by an alert system sent when the maximum load angle accepted by the neck in an adult is exceeded $\left(30^{\circ}\right.$ with respect to the imaginary vertical line on the back). This work contributes to the prevention of future injuries in the cervical areas according to the information provided by specialists in physical rehabilitation.
\end{abstract}

Artificial Vision, OpenPose, Text Neck

\begin{abstract}
Resumen
La visión artificial es una herramienta usada para comprender imágenes que se han analizado y procesado. $Y$ en aplicaciones de la salud y cuerpo humano no es la excepción, ya que ayudan a vectorizar el cuerpo y su movimiento, analizando los cambios entre los mismos. El objetivo principal del presente trabajo es el de desarrollar una aplicación móvil interactiva para el monitoreo, descripción y registro de las posturas corporales en las zonas del cuello y la espalda alta al hacer uso de dispositivos celulares. Se hace uso del algoritmo de OpenPose para identificación y registro de los puntos específicos de las zonas establecidas. En el proceso de análisis, el framework de Keras es utilizado con la finalidad de construir una red neuronal convolucional de aprendizaje profundo. Se diseña una interfaz gráfica de usuario con la finalidad de facilitar el uso e interpretación de mediciones. Además, se acompaña de un sistema de alerta enviada al sobrepasar el ángulo de carga máximo aceptado por el cuello en una persona adulta $\left(30^{\circ}\right.$ respecto a la línea vertical imaginaria en la espalda). Este trabajo contribuye en la prevención de futuras lesiones en las zonas cervicales de acuerdo con la información proporcionada por especialistas en rehabilitación física.
\end{abstract}

Visión Artificial, OpenPose, Text Neck

Citation: GARCÍA-CERVANTES, Heraclio, CARDONA-VILLALPANDO, Juan Carlos, BLANCO-MIRANDA, Alan David and CARRILLO-HERNÁNDEZ, Didia. Artificial vision system for the prevention of injuries in the upper back and neck areas based on the OpenPose algorithm. ECORFAN Journal-Taiwan. 2020. 4-8: 13-19

\footnotetext{
* Correspondence to Author (email: hgarcia@utleon.edu.mx)

$\dagger$ Researcher contributing as first author.
} 


\section{Introduction}

\section{Text Neck}

All technological advances have consequences and smart devices are no exception. Today's life of people centers on a mastery of computer technology. The excessive use of the mobile device in daily life tasks induces a problem called "Text Neck" (TN) [I, II], which affects the world population. TN, or "turtleneck posture", is an injury caused by repeated stress and pain from poor position in the use of electronic devices for long periods of time. Symptoms include pain in the neck, shoulders, head, and a change in the curvature of the spine $[\mathrm{I}-\mathrm{V}]$. If this syndrome is not treated or is corrected at the right time, the damage can be permanent, causing inflammation of the neck ligaments, muscles, tendons and nerves, which can lead to permanent arthritic changes [IX]. It can also cause a flattening of the spinal curve, early arthritis, compression of the disc, herniated disc etc. It is a health problem that is increasing and affects a large number of the population around the world.

The vertebral column is a bony network that protects the spinal cord, it is inserted at the base of the brain, at the level of the neck and ends at the hip; see figure 1 . The upper area, trunk and neck is the part where the injury and musculoskeletal problems occur due to poor posture when using the mobile phone [VI].

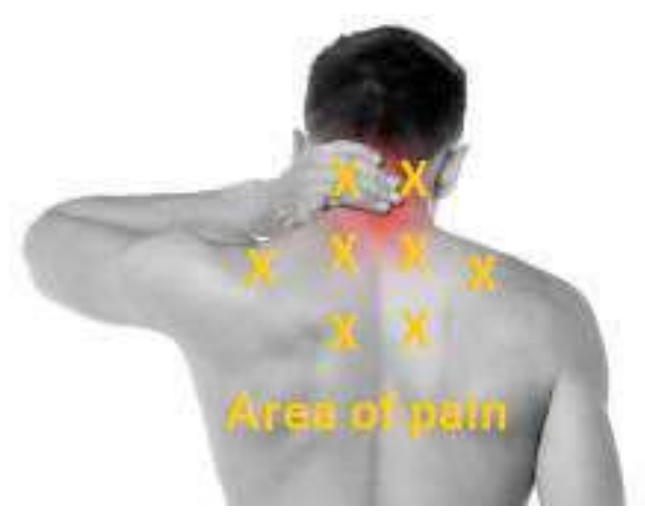

Figure 1 Pain area [6]

Users by adopting a prolonged posture when tilting their head towards the screen of the mobile device directly affects the spine, considering that depending on the degrees of inclination of the head, their weight increases depending on the angle, see Figure 2.
There Reports where studies have been made on the time that people spend on average using the mobile, it is concluded that it is a range that goes from 2.7 to 5.4 hours on average a person uses their device daily. The TN epidemic has become a global problem, it is identified that people who present pain in the neck and shoulders tend to have a higher level of anxiety and / or depression due to frequent discomfort. [VII].

Mobile devices are updated frequently, every day there are more applications so that people not only send messages or calls, but also contain games, books, music, cameras, videos, bank account, purchases, whatsapp, facebook, GPS , etc. By replacing a large number of activities allowing them to be carried out in a single device and the movement of people is restricted [I]. Given the circumstances, the Chiropractic and Physiotherapy Associations recommend limiting the activities of mobile devices, using computer equipment to answer emails or call instead of sending messages to avoid NT [VIII].

In a correct posture to avoid $\mathrm{TN}$ syndrome, the ears are aligned with the shoulders and shoulder blades, reducing the stress on the spine, see figure 2 first image [V, $\mathrm{VI}]$. According to the angle of inclination of the head, the force exerted on the cervical increases considerably, which is the main cause of the discomfort and problems caused by poor posture, as shown in Figure 2.

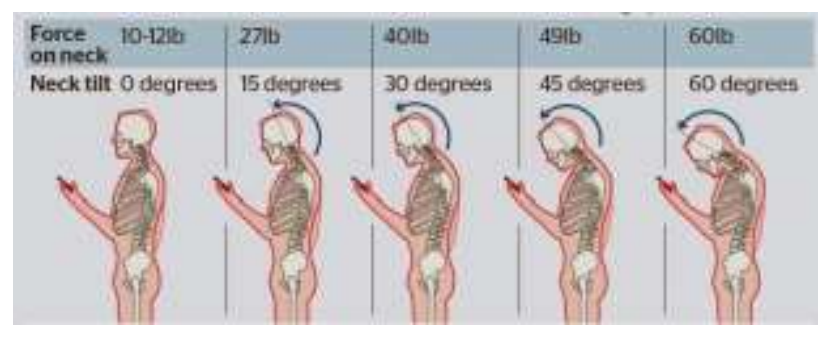

Figure 2 Variation of the force exerted by the head on the spinal column as the degree of inclination increases [VI]

One of the most important aspects for human beings is health, and we must constantly innovate in the development of new tools that allow us to analyze the different diseases that appear every day. Technological development always brings consequences and in this case it is no exception. 
The advancement in electronic devices, with a greater number of applications, causes people to spend more time using the mobile device, which causes stress on the upper part of the spine, which can be aggravated in injuries. $\mathrm{TN}$ syndrome is a relatively new health problem, but it is constantly growing due to the constant and excessive use of the mobile device, and development should begin for an efficient study in detecting it early and avoiding complication. This problem is found specifically in the area of the head, neck and back, since it is the part that we force when tilting the head to observe the cell phone. This inclination is the one that needs to be measured by means of its angle that determines the presence or absence of the syndrome and with it the detection of the body's posture, see figure 3 .

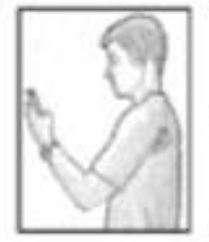

(a)

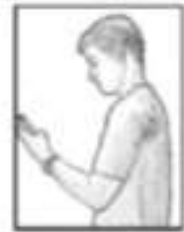

(b)

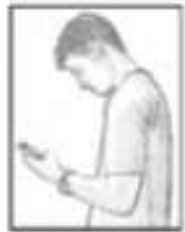

(c)

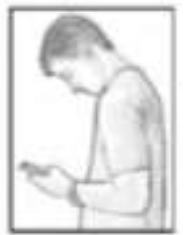

(d)
Figure 3 Different positions for viewing the mobile device [X]

TN syndrome is a problem in which it is necessary to intervene immediately, since around $67 \%$ of the world population uses cell phones. To carry out a correct approach it is necessary to be clear about the physiological effects that the use of technologies can cause. For this particular case, we will address the problem that cell phone use brings with it, and propose a solution to reduce or eradicate the negative effects caused by the use of smart devices.

The investigation of the technology of recognition of the posture in the use of the mobile, belongs to a branch of the investigation of the estimation of the posture of the human body. Before 2015, the coordinates of the joints were returned directly [XIII], then the literature [XIV] proposed the CPM method that uses a sequential convolutional architecture to express spatial information and texture information. The literature $[\mathrm{XV}]$ proposed an hourglass-type network structure, and most of the estimation algorithms for single-person Pose that appeared after 2016 are based on this model structure [XVI, XVII]
In this article, the OpenPose algorithm [XVIII, XIX] is used to extract the characteristics of the spatial positions of the central point of the neck and nose, and how this line is inclined with respect to an imaginary vertical line of the center of the upper back. The extracted feature maps marked with the bony nodes of the volunteers are used as a training set. Then, the Keras deep learning framework is used to build a deep learning network and thus the data set is used for network training. So that the model can be used to judge the posture during the use of a person's mobile in real time and generate alerts when the neck tilt limit is exceeded, thus avoiding excessive loads in the established area.

\section{Methodology}

\section{Neural Networks}

The brain is made up of nerve cells which connect with each other to form neural networks, where information received from the environment is received and processed. To later be sent to all systems of the body and perform the action.

A neural network is a processor of information which can be stored and available when needed.

There are different learning techniques that can be used in a variety of applications, among them, convolutional neural networks (CNN), which have attracted attention in recent years in vision systems and image analysis [4850 , medical image]. CNNs recognize visual patterns directly from raw image pixels. These networks look at small moles of the input image through neurons of several layers and different weights in each convolution, see Figure 4.

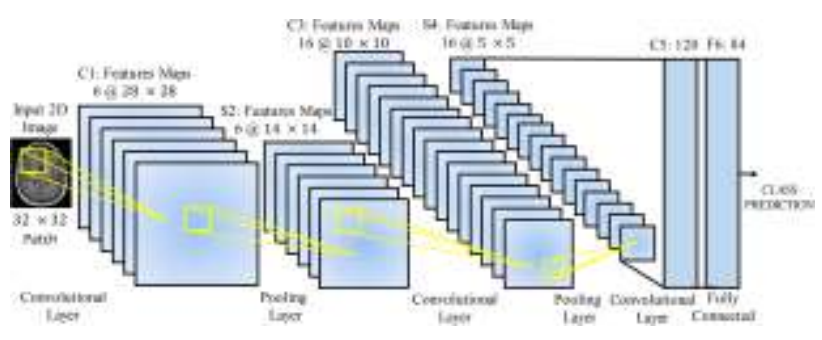

Figure 4 Architecture of a convolutional neural network for image classification. [XI] 
Each neuron or node in a CNN is governed by an activation function, which controls the output. Activation functions can be linear, sigmoid, tanh, rectified linear unit. In addition to using different types of grouping to split the image, reduce calculations, replace blocks, activate regions, etc. [XII].

In this research, convolutional neural networks will be used, these are the most frequently used for computer vision and are built of a series of layers that process the input image through filters in each convolution, which are the basis of the OpenPose algorithm.

\section{OpenPose algorithm}

One tool for extracting human posture is OpenPose. The OpenPose Human Body Attitude Recognition Project is an open source library developed by Carnegie Mellon University (CMU) based on convolutional neural networks and supervised learning and developed in the caffe framework [XVIII]. An estimate of attitude, such as human movement, facial expression, and proper finger movement can be achieved for one or more people, with excellent robustness [XIX]. OpenPose provides a bottomup approach to real-time estimation of multiperson gestures without the need for character detectors.

When loading the pre-trained OpenPose model, the algorithm will extract 18 body joints and 17 connection lines, see Figures 5 and 6. In the case of this work, only the points corresponding to the nose, neck, right shoulder and shoulder will be taken into account. left.

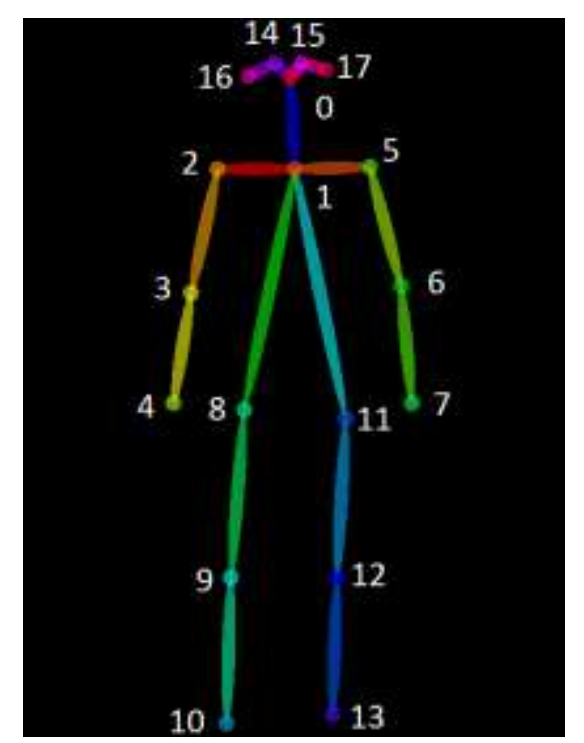

Figure 5 Skeleton data delivered by the OpenPose algorithm

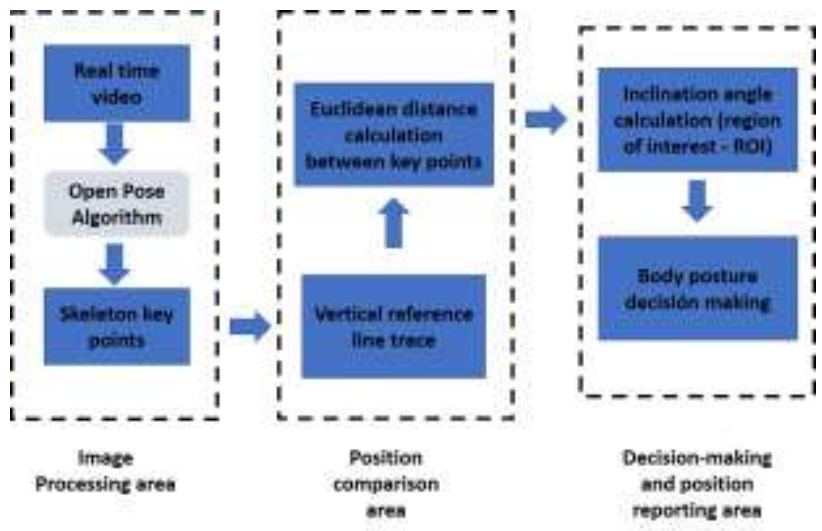

Figure 6 System architecture

\section{Results}

The results obtained with the implementation of the OpenPose algorithm in detecting the different postures of people while using the cell phone are shown below.

The generated interface shows the realtime visualization of the person's posture together with the key points, in addition to the lines that join them to show the posture (see Figure 8), while in Figure 7 a list appears with the coordinates of these points.

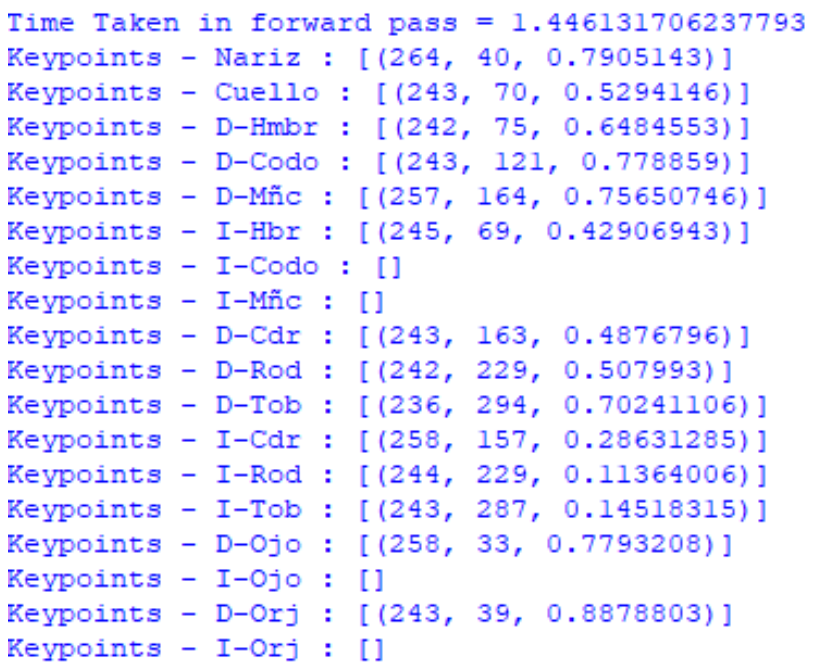

Figure 7 Coordinates of key points recorded by the OpenPose algorithm

Among the tests carried out, a webcam (VGA resolution) is used, capturing from the front and from the side.

In Figure 8, an example of registration is shown for the points from the shoulders to the head (this being the region of interest for the analysis). 


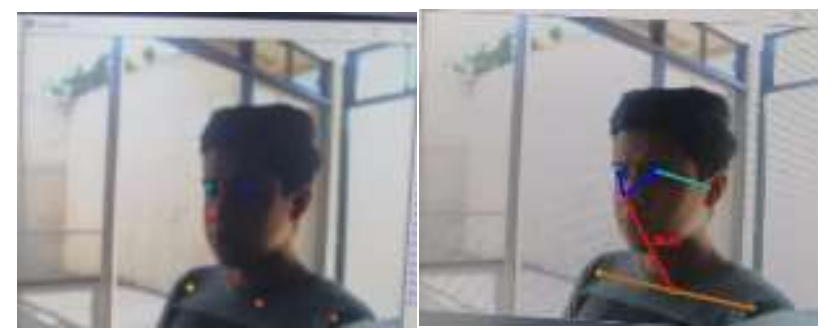

Figure 8 a) Positions of key points recorded by the OpenPose algorithm, b) Junction lines between key points for tilt angle measurement

Within the developed interface, when starting the video, the image with the line and the angle of inclination in the posture of the person are shown in Figure 9. Here the individual is within the range of the angle of inclination of the head of a proper position, because it shows an angle of 14.35 .

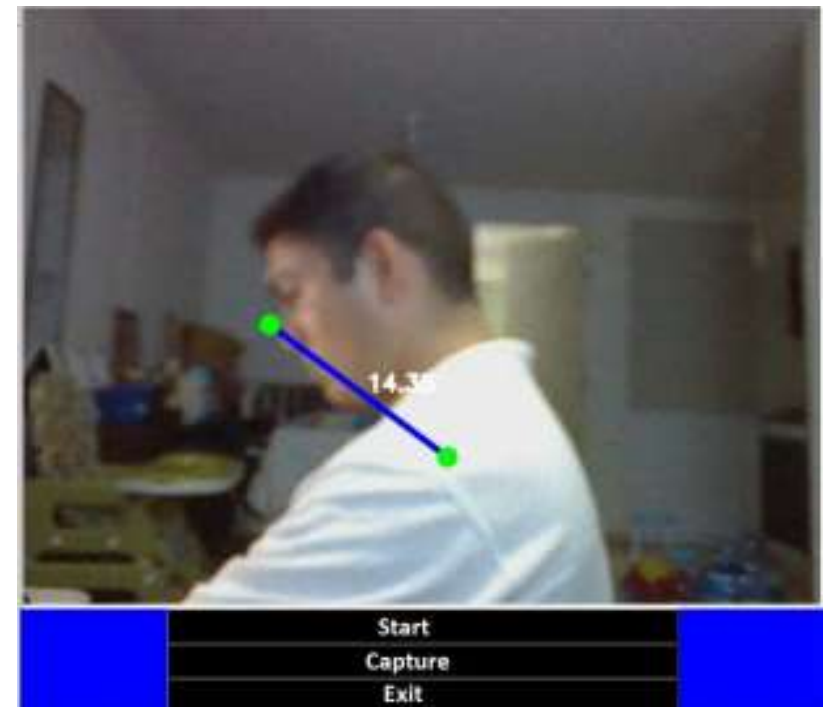

Figure 9 Measurement of head and neck tilt angle during cell phone use

According to what has been reviewed in the literature [VI], the critical angle to generate a posture alert is $15^{\circ}$ since excessive tension is generated for that angle of inclination and higher, which can cause future injuries. In order to create a warning about this situation, the application sends a push notification $[\mathrm{XX}]$ to the person and on the screen changes the color of the line that measures the angle to red, this being a visual alert (Figure 10 ).

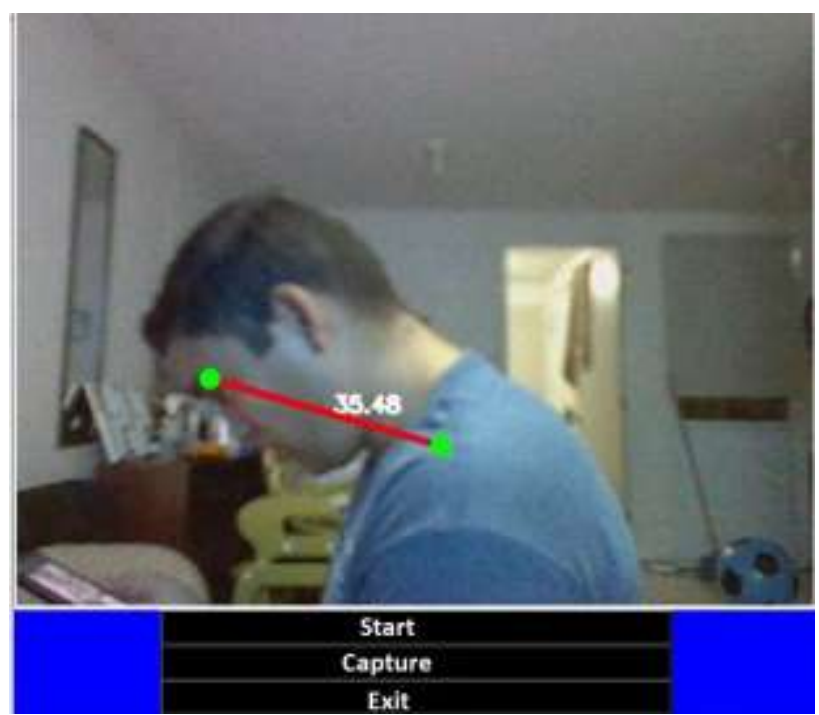

Figure 10 Detection of a high angle of inclination, with a bad posture when using the cell phone

The notification received by the user on his cell phone can be personalized and preset from the system settings. Figure 11 shows an example of the message received during a posture alert.

Ayer $\cdot 7: 08$ p. m.

Sent from your Twilio trial
account - Tu grado de
inclinación es 19.27 y tienes
problemas con tu postura
mar. $7: 08$ p. m.

Figure 11 Alert message sent by the developed interface

\section{Acknowledgments}

Thanks to the Technological University of León for the space and technical equipment provided to carry out this project. Also, to the physiotherapists Juan Pablo Lira and Armando Correa for the facilities provided for the information and documentation of this work.

\section{Conclusions}

In this work, a tilt recognition system was developed in the neck and upper back area, while using mobile devices, based on computer vision to find and correct poor posture in users.

The algorithm uses OpenCV to extract the video information captured by the monitor. Then OpenPose is used to extract the posture feature. 
A pre-trained network model was used, it was used to identify the posture during the use of the mobile device and the sending of notifications to the user when it exceeds the maximum allowed angle.

After actual testing, the user's tilt angle can be effectively identified, helping to develop good habits and prevent future injury to the tested area. It is very significant to reinforce learning in an area that is currently growing more and more and that takes great value from what is expected of new technologies, in favor of human health.

As a future development, the system will be implemented in a convolutional neural network using the Keras deep learning framework to train data sets taken from a physical rehabilitation room, where experts in the area will validate the delivered results and a statistical analysis will be generated. of its precision.

This study also opens up the possibility of attending to other types of alterations or disorders of the upper back and neck, such as cervical rectifications, the result of automobile or sports accidents.

\section{References}

[I] Vate U-Lan, P. (2015). "Text Neck Epidemic: a Growing Problem for Smart Phone Users in Thailand". Vol 23, No 3, pp27-32.

[II] Gupta, V.K., Arora, S., and Gupta, M. (2013). "Computer-related illnesses and Facebook syndrome: what are they and how do we tackle them". Med Update, Vol. 23, pp. 6769 .

[III] Park, J., Kim, J., Kim, K., Kim, N., Choi, I., Lee, S., and Yim, J. (2015). "The effects of heavy smartphone use on the cervical angle, pain threshold of neck muscles and depression".

[IV] Park, J., Kim, K., Kim, N., Choi, I., Lee, S., Tak, S., and Yim, J. (2015). "A Comparison of Cervical Flexion, Pain, and Clinical Depression in Frequency of Smartphone Use". Int. J. BioSci. Bio- Technol., Vol. 7, No. 3, pp. 183-190.

[V] Hansraj, K.K. (2014). "Assessment of stresses in the cervical spine caused by posture and position of the head". Surg. Technol. Int.
[VI] Neupane, S, Ifthikar, U.T. and Mathew, A. (2017). "Text Neck Syndrome - Systematic Review", vol-23, No 3, pp 141-148.

[VII] Isaac, C. "Potential Negative Effects Toward Health and Well-Being in Relation to Smart Device Use". the Highlands College at Digital Commons@ Montana Tech, 2014.

[VIII] The American Chiropractic Association (ACA). "Preventing Text Neck". Preventing Text Neck, Oct-2011. <http://www.acatoday.org/JacaDisplay1. $\mathrm{cfm}$ ?CID $=4637 \&$ DisType $=\mathrm{PDF}>$. Accessed 20 October 2015.

[IX] Samani, P.P., Athavale, N.A., Shyam, A. and Sancheti, A.K. (2018). Awareness of text neck syndrome in young-adult population, vol5, No 8, pp 3335.

[X] Moreira-Damasceno, G., Sá-Ferreira, A. Calazans-Nogueira, L. A., Jandre-Reis, F. J., Santana-Andrade, I. C. and Meziat-Filho, N. (2018). Text neck and neck pain in 18-21-yearold young adults, European Spine Journal, vol27, pp-1249-1254.

[XI] Anwar, S.M., Majid, M., Qayyum, A., Awais, M., Alnowami, M. and Khan, M. K. (2018). Medical Image Analysis using Convolutional Neural Networks: A Review, J Med Syst, vol-42, pp-226.

[XII] LeCun, Y., Bengio, Y., and Hinton, G.,(2015). Deep learning. Nature. vol-521,pp436-444.

[XIII] Toshev A, Szegedy C. DeepPose: Human Pose Estimation via Deep Neural Networks [J]. 2013.

[XIV] Wei S E, Ramakrishna V, Kanade T, et al. Convolutional Pose Machines [C]// CVPR. IEEE, 2016.

[XV] Newell A, Yang K, Deng J. Stacked Hourglass Networks for Human Pose Estimation [J]. 2016.

[XVI] Yang W, Li S, Ouyang W, et al. Learning Feature Pyramids for Human Pose Estimation [J]. 2017. 
[XVII] Ke L, Chang M C, Qi H, et al. MultiScale Structure-Aware Network for Human Pose Estimation [J]. 2018.

[XVIII] Cao Z, Simon T, Wei S E, et al. Realtime Multi-Person 2D Pose Estimation using Part Affinity Fields [J]. 2016.

[XIX] Qiao S, Wang Y, Jian L. Real-time human gesture grading based on OpenPose [C]// 2017 10 th

International Congress on Image and Signal Processing, BioMedical Engineering and Informatics (CISP-BMEI). 2018.

[XX] Okoshi, Tadashi and Tsubouchi, Kota and Tokuda, Hideyuki, "Real-World Product Deployment of Adaptive Push Notification Scheduling on Smartphones", Association for Computing Machinery, New York, NY, USA. (2019) doi.org/10.1145/3292500.3330732. 